\title{
Smart Irrigation System using Iot and Image Processing
}

\author{
V R Balaji
}

\begin{abstract}
Today the farmers are finding difficulty in monitoring the field about moisture content and temperature of the field. Hence, this project is developed to monitor the farms using the concept of Internet of Things (IoT) and Image processing. The solar panel is used in our project to utilize the renewable energy which acts as an uninterruptable power sources. The Battery is used to store the energy from the Solar panel via Charge Controller (MPPT). The Soil moisture sensor and the Humidity sensors are used to monitor the moisture content of the soil and also the temperature and humidity of the surroundings. The DC Pump can be controlled automatically (switched ON/OFF) by the Arduino, Ethernet shield and Relay, based on the soil moisture and the temperature level. These data's and the condition of the DC Pump are send to the BLYNK ANDROID App to monitor the farms and lands by simply login to our account, and the condition of the DC Pump is also notified to the user Email with the help of internet connections by using Arduino and Ethernet shield. In image processing technique the health condition of the crop is intimated to the user with the help of Raspberry pi and webcam. The Raspberry pi captures the images of the crops and checks the images of the crops to detect its health condition whether it is infected or in Healthy condition. And the condition of the crops is intimated to the user by sending its images and health condition of the crops by E-mail notifications. This can be monitored from any part of the world.

Keywords - MPPT (Maximum Power Point Tracking), IoT (Internet of Things), DC (Direct Current)
\end{abstract}

\section{INTRODUCTION}

Agriculture plays a major role in our Indian Economy. Many technologies came to make the agricultural work very easy. Many enthusiasts done project for the easy implementation of the agricultural work. One of them includes automatic seeding and spraying of the fertilizers. Because some people have their own lands in their villages. But they are working in urban areas. So they don't have the time to monitor their fields and periodic maintenance. So the designing of Automatic irrigation system is required. In our project, Based on soil moisture level, and temperature level the irrigation can be done automatically with the help of Arduino and Ethernet shield. The temperature and soil moisture level and the status of the DC pump is intimated to the users BLYNK app account and Email notifications. Image processing technique is used to know the health condition of the crop, by using Raspberry pi 3, an USB web camera is used for all time monitoring of crops. The Condition of the crops is intimated to the user via Email easily without human intervention.

V R Balaji, Assistant professor Department of EEE Kumaraguru college of Technology Coimbatore, India.(E-mail: cnt2gee@gmail.com)
Revised Manuscript Received on August 14, 2019.

\section{INTERNET OF THINGS}

\section{INTRODUCTION}

This chapter deals with the description of the IoT and its key features.

\section{A) IOT - KEY FEATURES}

1) AI-IOT- is the system that makes works smart and easier in data maintenance and storing.

2) Connectivity- Variety of wired and wireless connectivity standards are available depends on the application needs.

3) Sensors - sensors are used to sense and deliver the information from physical world to the cloud.

4) Security- Iot protects the user and manufacturers IP, data and privacy from malicious activity.

5) Small Devices - IoT doesn't use any larger hardware devices for data storing and maintenance.

6) Power- Many IoT applications needs to run for years over batteries and reduce overall energy consumption.

7) Integration- IoT integrates all the above process and controls the equipment or machines depends upon the user needs.

\section{METHODOLOGY}

\section{1) INTRODUCTION}

This chapter contains the Block diagram and Circuit diagram, Hardware used and its functions.

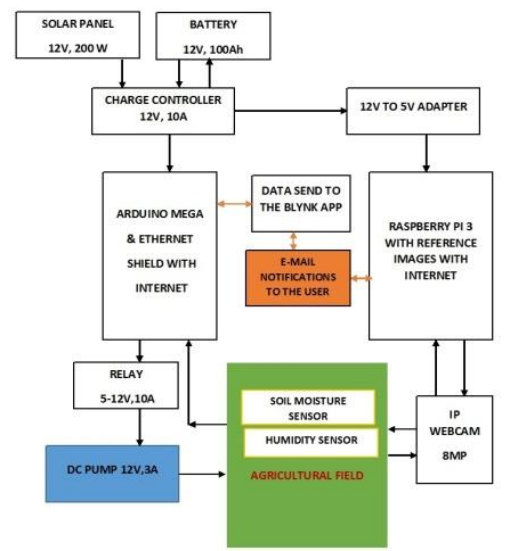

Fig 1 BLOCK DIAGRAM

The block diagram consists of various blocks such as Solar panel connectecd with Charge controller Connected with Battery. It is connected through $12 \mathrm{v}-5 \mathrm{v}$ converter. The

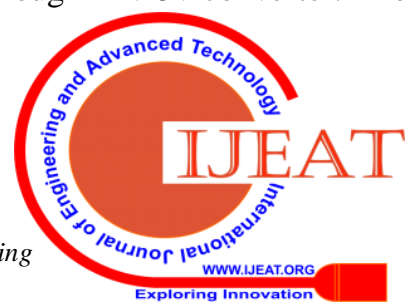


Arduino mega Controller is dumped with programs for automatic control of motor. The Ethernet shield is used for external communication .More over Voltage Relay, Soil moisture sensor, Humidity sensor are implemented to sense various field parameters. The DC pump is used to avoid converter stage. The Raspberry pi 3 is used for sensing image signals through Usb web camera with inbuilt Memory card.

\section{2) CIRCUIT DIAGRAM}

The figure show the circuit diagram of the proposed work.

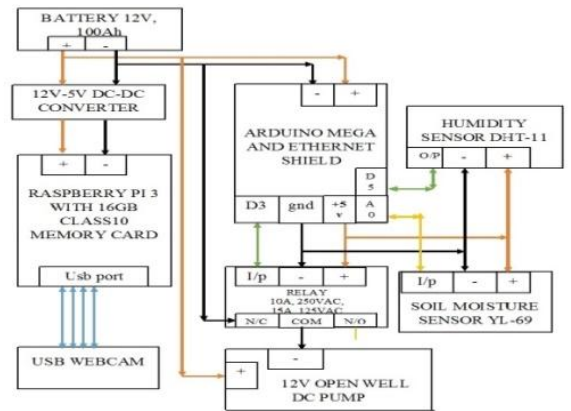

FIG 2- CIRCUIT DIAGRAM

3) HARDWARE USED AND ITS FUNCTIONS

(i)SOLAR PANEL

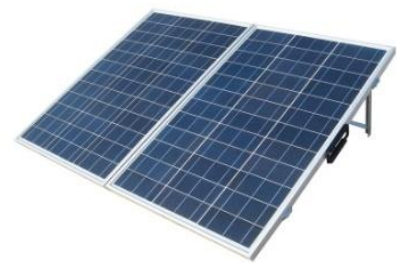

FIG 3 - (2*100) 200WATTS SOLAR PANEL

The two 100 watts panel is used to generate electricity and those panels are connected in parallel because whole system operates on $12 \mathrm{~V}$. The specifications of the each PV solar panel are as follows:

OPEN CIRCUIT VOLTAGE : 19V

SHORT CIRCUIT VOLTAGE: $12 \mathrm{~V}$

SHORT CIRCUIT CURRENT: $5.5 \mathrm{~A}$

TYPE: POLYCRYSTALLINE

4) CHARGE CONTROLLER (MPPT)

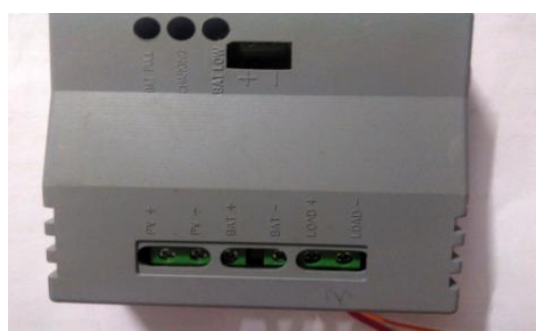

FIG 4- CHARGE CONTROLLER

The function of the charge controller is used charge the battery in case of low battery and it disconnects the solar panel from battery if it is fully charged. The charging current should not exceed the rated charging current of the battery. If it exceeds the limit the life time of the battery be reduced. The specifications of the charge controller is.

VOLTAGE: $12 \mathrm{~V}$
CURRENT: 10A

TYPE: MPPT

5) BATTERY

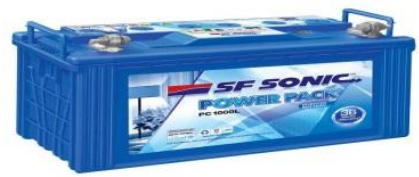

FIG 5 - TUBULAR BATTERY

The Battery is used to store the energy from the solar panel. It acts as a power source for the whole circuit. The specifications of the battery is,

VOLTAGE: $12 \mathrm{~V}$

CAPACITY: $100 \mathrm{Ah}$

CHARGING CURRENT RANGE: 10-15A

TYPE: TUBULAR

6) 12V-5V USB CONVERTER

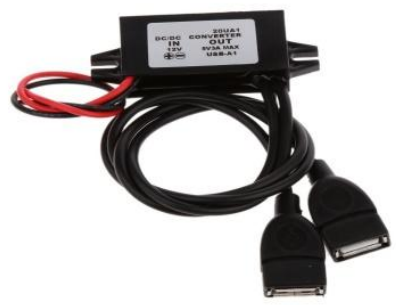

FIG 6 -12V TO 5V USB CONVERTER

The $12 \mathrm{~V}$ TO $5 \mathrm{~V}$ USB converter which acts as a source for ARDUINO MEGA and RASPBERRY PI 3. It is connected to the charge controller. The specifications of the converter is,
INPUT VOLTAGE: $12 \mathrm{~V}$
OUTPUT VOLTAGE: 5V
INPUT CURRENT: $1.25 \mathrm{~A}$
OUTPUT CURRENT: 5A

\section{7) ARDUINO MEGA}

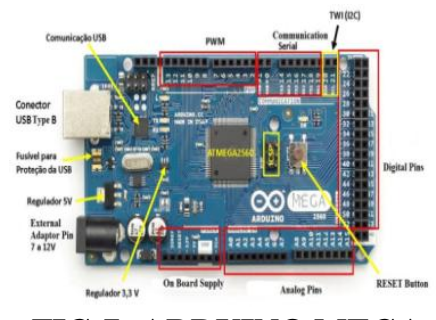

FIG 7- ARDUINO MEGA

The Arduino mega is controller used for receiving the sensor values from the field. By installing the library files and upload them in Arduino. Depending upon the sensor values it controls the DC pump and sends the notifications to the user. The specifications of the Arduino mega is

Published By: 


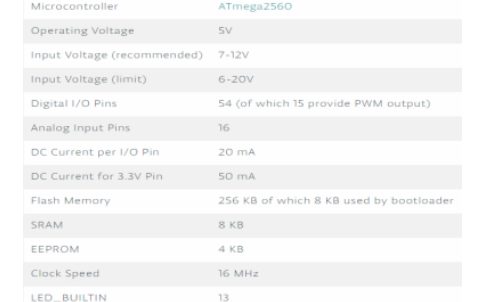

FIG 8- SPECIFICATIONS OF ARDUINO MEGA

8) ETHERNET SHIELD

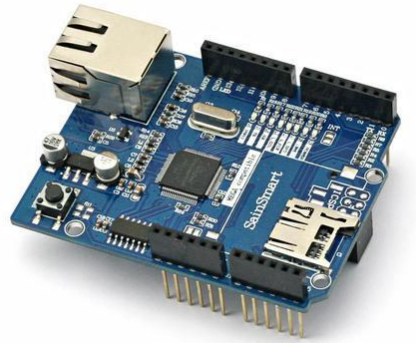

The Ethernet shield is used to provide internet connections to the Arduino by installing Ethernet library files in the Arduino mega. It is mounted above the Arduino. It works with the help of Arduino supply. It have other features like memory card slot for storage purpose, reset button, Analog and digital pins slot for input and output process. It is used to send email notifications to the user and to notify the sensor values in the BLYNK app.

9) RELAY

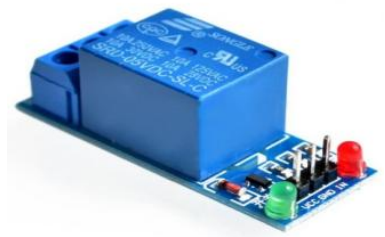

FIG 10 - RELAY

A $5 \mathrm{~V}-230 \mathrm{~V}$ voltage based relay is used to control the $12 \mathrm{~V}$ DC pump. It consists of three parts NC (NORMALLY CLOSED), NO (NORMALLY OPEN), and a common terminal. Depends upon the control signal from Arduino the NO becomes NC to turn ON the DC pump and NC becomes NO to turn OFF the DC pump.

\section{0) SOIL MOISTURE SENSORS}

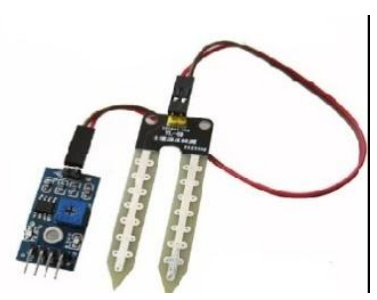

\section{FIG 11 SOIL MOISTURE SENSOR}

YL-69 Soil moisture sensor is used to know the moisture level of the soil. By this value the DC pump can be controlled through ARDUINO. The moisture level differ for different plant, climatic condition the plant growth. Even
FIG 9 - ETHERNET SHIELD

high moisturizing level in the plant can affect the plant. Good moisturizing will improve nutrient uptake. The difference for watering the plants will be based on the type of plants. The Specifications of soil moisture sensor are

\begin{tabular}{|c|c|c|c|c|c|}
\hline Item & Condition & Min & pic & Max & \\
\hline Voltage & $\cdot$ & 3.3 & 1 & 5 & V \\
\hline Current & - & 0 & 1 & 35 & $\mathrm{~mA}$ \\
\hline Output Voltage & Supply Voltage $5 \mathrm{~V}$ & 0 & $\sim$ & 4.2 & V \\
\hline \multirow{3}{*}{ Output Value } & Sensor in dry soil & 0 & $\sim$ & 300 & 1 \\
\hline & Sensor in humid soil & 300 & $\sim$ & 700 & 1 \\
\hline & Sensor in water & 700 & $\sim$ & 950 & 1 \\
\hline
\end{tabular}

\section{FIG 12 SOIL MOISTURE SENSOR SPECIFICAIONS}

Features of the YL-69

- Sensitivity can be easily adjustable

- Digital output is simple and accurate

- Threshold level can be configured

- The value is indicated by output pin

- Inbuilt ADC converter

\section{1) HUMIDITY SENSOR}

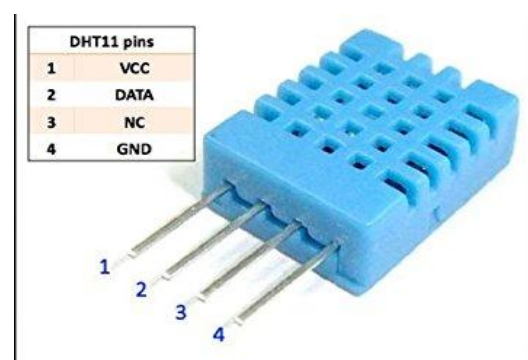

\section{FIG 13 HUMIDITY SENSOR}

The DHT 11 sensor is used to know the humidity and temperature level in the atmosphere. Depending upon these values the DC pump be controlled with the Arduino. The features and specifications of the DHT 11 sensor is

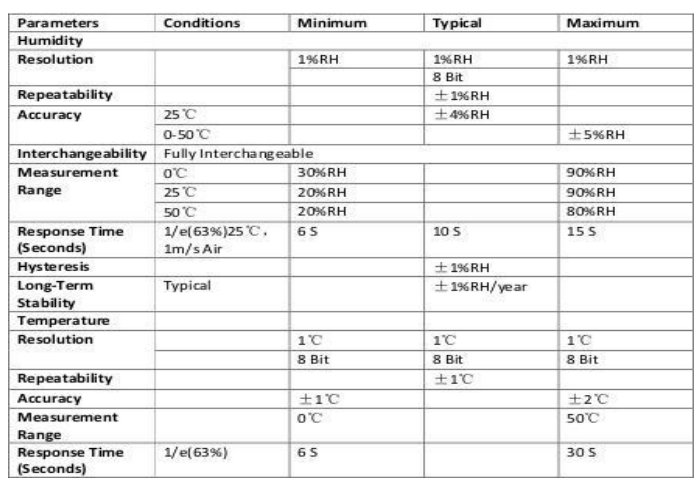

FIG 14 DHT 11 SENSOR SPECIFICATIONS

\section{2) DC PUMP MOTOR}

It is an open well type water pump. It works on $12 \mathrm{~V} \mathrm{DC}$ supply. It is extremely simple and easy to use. The suitable pipe is connected to the pump at inlet and outlet. The motor is small, compact and light. Depends upon the sensor values it can be controlled with the help of Arduino and relay, Battery. It have in build thermal protection.

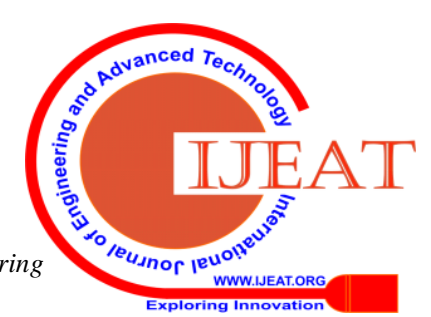




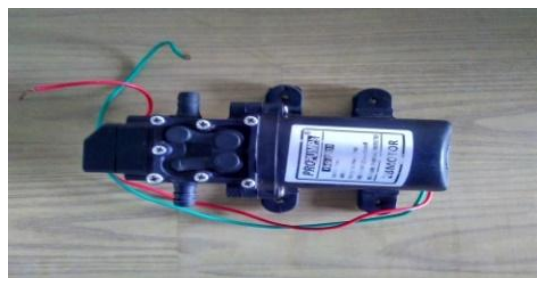

FIG 15-12V DC OPEN WELL PUMP

The specifications of the DC pump is

VOLTAGE $-12 \mathrm{~V}$

CURRENT-3A

HEAD - 2 METERS

FLOW RATE- 10LTS / 3 MIN

13) RASPBERRY PI 3

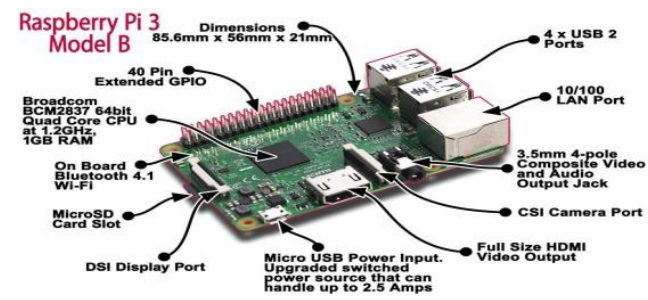

FIG 16- RASPBERRY PI 3

The Raspberry pi 3 model is used for image processing technique by installing Raspbian OS and other library files. It operates at $5 \mathrm{~V}$ supply. Its function is to find whether the crop or leaf is in healthy condition or infected condition. It also send email notifications to the user about the condition of the crops or leaves. The features of the Raspberry pi 3 is

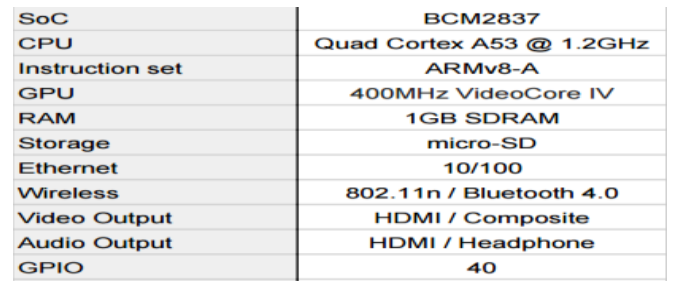

FIG 17 - FEATURES OF RASPBERRY PI 3

14) $s s$

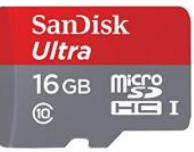

FIG 17-16 GB MEMORY CARD

A 16GB CLASS 10 memory card is placed on the raspberry pi memory card slot. It is used to store the Raspbian OS and OPEN CV library files and to store the images of the crops or leaves.

\section{5) USB WEBCAMERA}

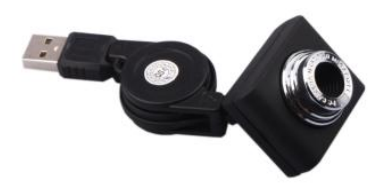

FIG 18- USB WEB CAMERA
A 5Mega Pixel USB camera is used to capture the image of the crops or leaves for every interval of time. The USB web camera is connected to the raspberry pi USB port.

\section{HARDWARE AND SOFTWARE IMPLEMENTATION \& RESULTS}

The hardware and software implementation of SMART IRRIGATION SYSTEM USING IOT AND IMAGE PROCESSING has been discussed.

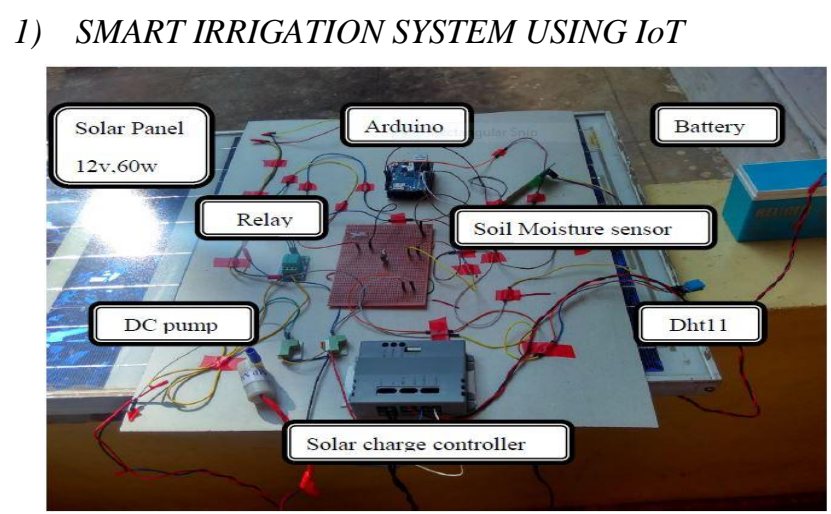

FIG 19- SMART IRRIGATION SYSTEM WORKING MODEL

In SMART IRRIGATION SYSTEM USING IOT it contains solar panel, charge controller, battery, Arduino, Ethernet shield, relay, soil moisture sensor, humidity sensor and DC pump. The solar which acts as a source and generates electricity. These charges are stored in the battery via charge controller. The Arduino, soil moisture sensor, humidity sensor, DC pump needs supply from the battery via charge controller. Depending upon soil moisture sensor and humidity sensor readings the DC pump can be controlled ON and OFF with the help of relay and Arduino. These data are feed to the BLYNK app and sends email notifications with the help internet by using Arduino and Ethernet shield.

\section{2) IMAGE PROCESSING}

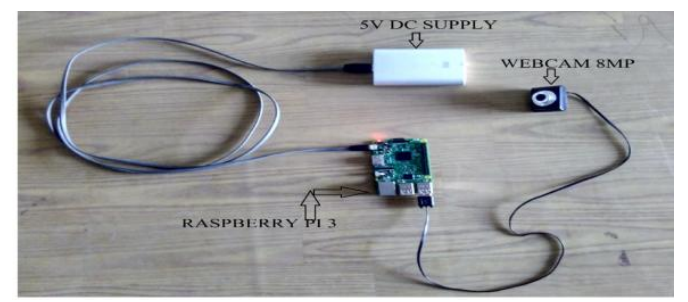

FIG 20 - IMAGE PROCESSING WORKING MODEL

The IMAGE PROCESSING technique uses Raspberry pi 3 , memory card, USB web camera. Initially a timer program library file is installed on the memory card and the USB WEB camera is used to capture the image of the crops/plants for a time period of interval. The Raspberry pi process the pixels in the images captured by the web camera to find whether the plants leaves are in HEALTHY or PARTIALLY INFECTED or INFECTED condition. Then the condition of the crops/plants are send to the users email with pictures.

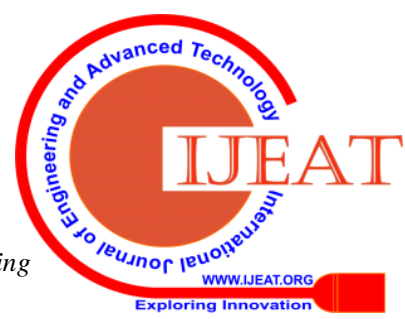




\section{3) SOFTWARE IMPLEMENTATION \\ (i) SMART IRRIGATION USING IoT}

In this BLYNK ANDROID app and email is used to send notifications to the user by installing BLYNK library files in the Arduino.

\section{BLYNK APP AND EMAIL}

In this proposed, BLYNK android App is used for monitoring the soil moisture and humidity sensor readings and status of the DC pump. By simply creating our own account and we have to configure the Hardware of the project. There are many number of widgets present in the Application. We use only three of them. They are

a) LED widget: For the indication of the status of the DC pump.

b) Email widget: For sending the email notification to the user about the status of the DC pump.

c) Gauge widget: For displaying the soil moisture, humidity sensor values.

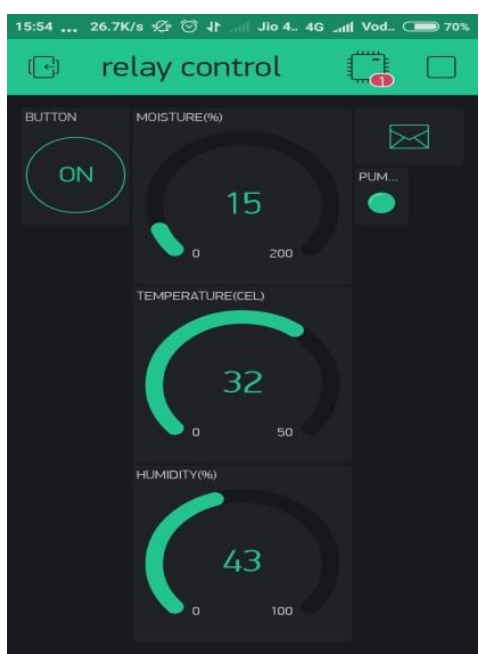

FIG-21. BLYNK APP

The above screenshot of the BLYNK android app dashboard is for monitoring the soil moisture and the temperature sensor readings in the field and it is updated periodically and the user can viewed it from anywhere. The DC pump status whether it is ON/OFF is indicated through GREEN LED on the right side of the dashboard. But in the above image, the soil moisture is $\mathbf{1 5 \%}$ and the temperature is normal. So the field is in dry condition. Hence it is time to irrigate the land. So, the pump is turned $\mathbf{O N}$ by the ARDUINO with the help of Relay switch and is indicated by Green LED. But during the wet conditions, the moisture level is greater than $40 \%$. For that the green LED turned to black. This indicates that the pump is in OFF condition.

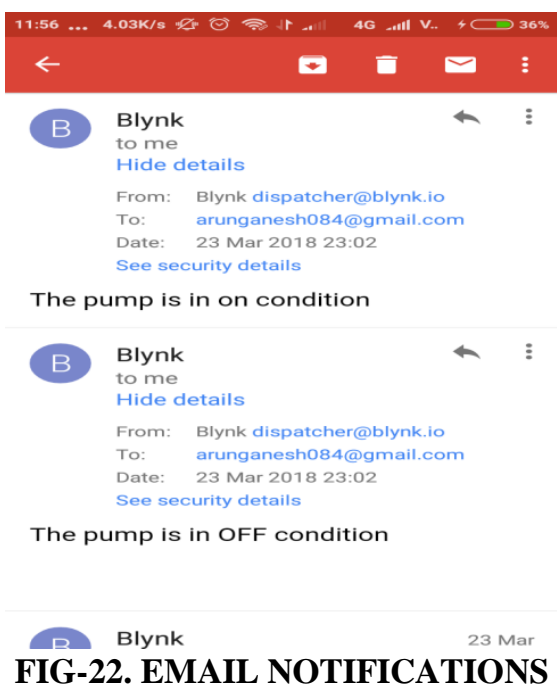

The status of the pump is also intimated to the user via Email which is done by BLYNK app Email widget in the top right corner of the dashboard.

\section{4) IMAGE PROCESSING}

In image processing technique OPEN $\mathrm{CV}$ and RASPBIAN OS is installed on the Raspberry pi 3.

OPEN CV is an open source programming software. It runs on the following operating system WINDOWS, LINUX, IOS, MAC OS etc. It runs on the following programming language $\mathrm{C}, \mathrm{C}++, \mathrm{RUBY}, \mathrm{PYTHON}$, MATLAB etc. In this work LINUX OS and PYTHON program is used. It is used to send the Email notifications to the user mail about the conditions of the crops or leaves.

5) output and results

This chapter deals with the description of output and results of the proposed work.

\section{(i) SMART IRRIGATION SYSTEM USING IoT}
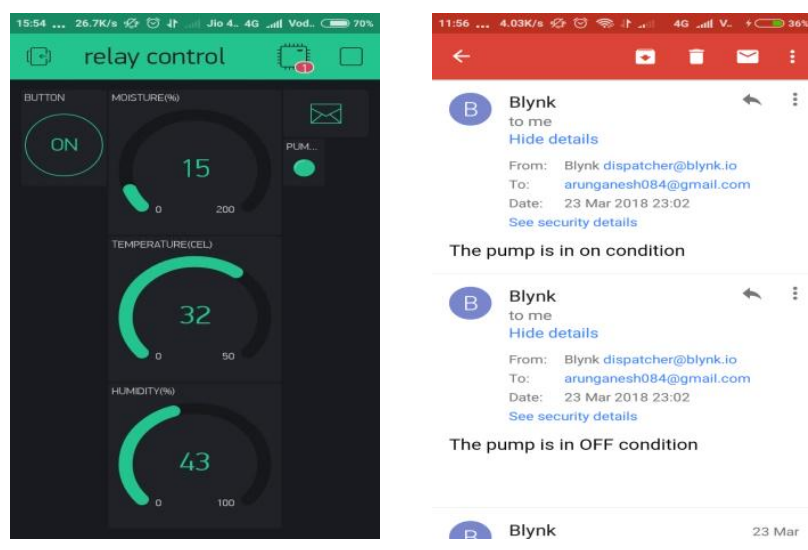

FIG 23, 24- SMART IRRIGATION SYSTEM NOTIFICATIONS TO THE USER ID

(ii) IMAGE PROCESSING CONDITION OF THE CROPS

(a) HEALTHY CONDITION 


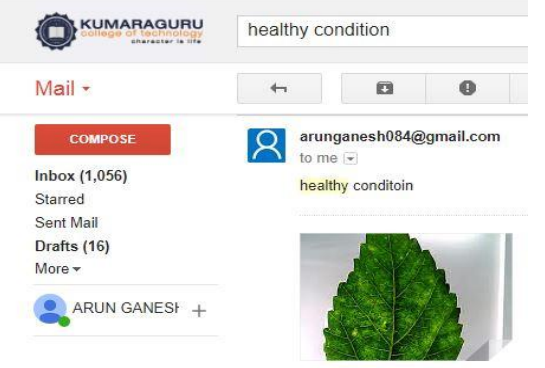

FIG 25- HEALTHY CONDITION NOTIFICATIONS

(b) PARTIALLY INFECTED CONDITION

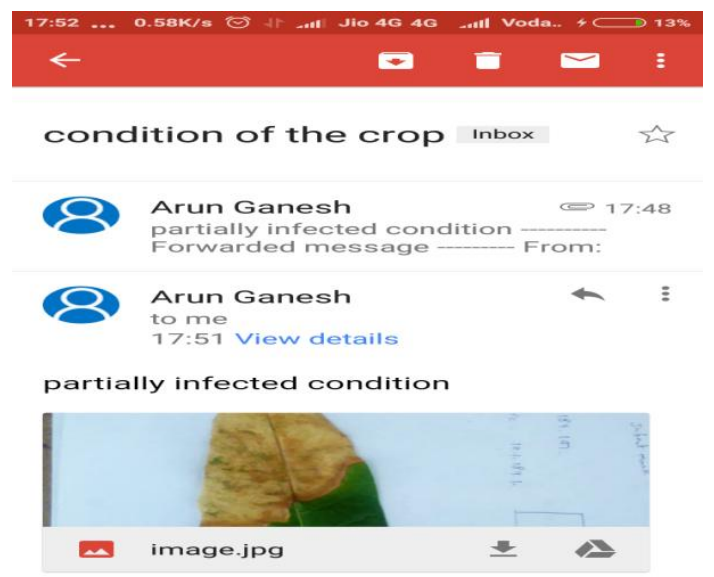

FIG 26- PARTIALLY INFECTEDCONDITION NOTIFICATIONS

(c) INFECTED CONDITION

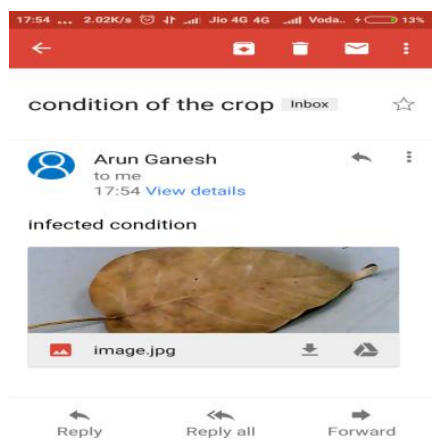

FIG 25-INFECTED CONDITION NOTIFICATIONS

\section{CONCLUSION}

This proposed work is made to help the farmers and make their harvest economical. The wastage of water and the consumption of power by motor can be reduced so that they are conserved for the future purpose. It provides complete monitoring action of sensors in fields that is very easy to monitor the field. In IMAGE PROCESSING the health condition of the crops is intimated to the user. Thus the project has been completed successfully.

\section{REFERENCES}

1. Dr.N.Prakash, V R.Balaji, M.Sudha, "solar powered automated irrigation system for agriculture", International Journal of Advanced Engineering Technology, Vol. VII,Issue II, page No: 1225-1233,April-June,2016.

2. V R.Balaji, Dr.N.Prakash," IoT Based Smart Security and Monitoring Devices for Agriculture", International Journal of
Pure and Applied Mathematics, Volume 116,No. 11 , page No: 121-129,2017.

3. V R.Balaji, M.Sudha, "Solar Powered Auto Irrigation System", International Journal of Emerging Technology in Computer Science \& Electronics, Volume 20 ,Issue 2, ISSN: 0976-1353, February 2016.

4. Nikesh Gondchawar, Dr. R.S.Kawitkar, "IoT Based Smart Agriculture",International Journal on recent and innovation trends in Computing and Communication, Volume 5, Issue 2 , PP 177-181, ISSN: 2321-8169, Feb 2016.

5. Aaditya Jain, Bhuwnesh Sharma, Pawan Gupta, "Internet of things: architecture, security goals and challenges- A survey" International journal of innovative research in science and engineering, Volume 2, Issue 4, PP 154-163, ISSN: 24549665, April 2016.

6. Juan Felipe Corso Arias., Yeison Julian Camargo Barajas., Juan Leonardo Ramirez Lopez., ,„,Wireless Sensor System According to the Concept of Internet of Things ${ }^{\text {ecee }}$, International Journal of AdvancedComputer Science and Information Technology, Volume 3,Issue 3,ISSN: 2296 1739, Mar 2014.

7. Dr.V.Vidya Devi,G.Meena Kumari, "Real- Time Automation and Monitoring System for Modernized Agriculture" International Journal of Review and Research in Applied Sciences and Engineering (IJRRASE) ,Volume 3, PP 712,ISSN: 2231-0061X, March 2013. 